\title{
Histo-pathological study of Medulloblastoma at tertiary care center: A 3 year retro-prospective study
}

\author{
Authors \\ Dr Arvindra Rahul ${ }^{1}$, Dr Sudha Iyengar ${ }^{2 *}$, Dr K S Mangal ${ }^{3}$, Dr Ajay Patel \\ ${ }^{1,4}$ Resident, Department of Pathology, G. R. Medical College, Gwalior \\ ${ }^{2}$ Professor, Department of Pathology, G. R. Medical College, Gwalior \\ ${ }^{3}$ Head of Department, Department of Pathology, G. R. Medical College, Gwalior \\ *Corresponding Author \\ Dr Sudha Iyengar
}

Professor, Department of Pathology, G. R. Medical College, Gwalior, MP, India

\begin{abstract}
Aim: Medulloblastoma is one of the most common brain tumors in the pediatric age group. Being of common occurrence, the epidemiology should be well understood to help in the management. The aim of present study is to analyze and correlate the clinicopathological features of medulloblastoma in a tertiary care center.

Method: It is a retro-prospective study from October 2015 to October 2018 (3 years) conducted in Department of Pathology, Gajraraja medical college Gwalior. Demographic data and clinical parameters of 19 cases were recorded and subsequently histopathology was studied. Data was analyzed and variables were correlated.

Results: Majority of patients were males (68.42\%) and of less than 12 years of age (78.94\%). Most common presenting complaint was headache $(89.47 \%)$ and frequent clinical finding was raised intracranial pressure (89.47) and hydrocephalus (84.21\%). All of the tumors were located in infratentorial region of brain. Histologically all the tumors were of classical variant except for one case which was diagnosed as desmoplatic variant on histology.

Conclusion: Medulloblastoma is a common malignancy in the pediatric population, accounting for $25 \%$ of all childhood brain tumors and relatively uncommon in adults. Surgery is the mainstay of treatment followed by craniospinal irradiation. Histological confirmation of all posterior fossa tumors is essential for the management of this potentially curable tumor.
\end{abstract}

\section{Introduction}

Medulloblastoma is an embyonal neuroepithelial tumor arising in cerebellum or dorsal brain stem, presenting mainly in childhood ${ }^{[1]}$. Medulloblastoma most frequently arises at the level of the fourth ventricle within the posterior fossa. Accordingly, common presenting symptoms are consistent with obstructive hydrocephalus or cerebellar dysfunction including headache, vomiting, gait disturbance, and 
imbalance $^{[2,3]}$. Cranial nerve palsies can be seen and in infants, macrocephaly can be prominent ${ }^{[3]}$. Average time from symptom onset to diagnosis ranges from 2 to 6 months ${ }^{[2,3]}$. Subsequent to surgical excision, despite radiation and chemotherapy, $30-50 \%$ of affected patients do not survive for 5 years, and post treatment cognitive deficits are common in those who do survive that long ${ }^{[4-7]}$. These tumors are usually staged clinically. Various clinical prognostic factors studied are found to be inconclusive. However, despite introduction of molecular classification of Medulloblastoma, histology plays a crucial part in diagnosis and prognostication of Medulloblastoma. With this study we aim to identify the prevalence, clinical behavior and histological spectrum of Medulloblastoma in our tertiary care center.

\section{Material and Method}

It is a 3 year retro-prospective study from October 2015 to October 2018. The specimens were received in Department of Pathology G.R. Medical College from the Neurosurgery Department of JA Hospital \& Group Gwalior. Specimens in Formalin were received. After that following procedures performed in department of pathology;

- Proper labeling of the specimen was checked or done before further processing.

- Gross examination of the specimen was done which includes

1. Site, Size, shape, color, appearance on surface, and consistency of Specimen.

2. Cutting of specimen to observe color, consistency and content of specimen.

3. Biting of specimen for further procedures.

- Further procedures include; fixation, dehydration, clearing, embedding, microtomy, staining and mounting of specimen were done as per standard procedures of our department. Staining was done with routine hematoxylin and eosin stain. Mounting was done with DPX (distyrene, plasticizer and xylene,)

- Prepared slides were examined under binocular microscope make Olympus using objective lens of 10x (low power) and 40x (high power) with the eye piece of 5/10x.

- Reporting and diagnosis of Medulloblastoma were done as per WHO criteria.

The data was collected, retrieved, tabulated, summarized and compared statistically by frequency distribution and percentage Proportion. Chi-square (X2) test was applied to evaluate the significant ( $p$-value) ratio of difference statistically using EpiCalc 2000 software.

\section{Result}

In the 3 year duration of the study, 19 specimens received in department of Pathology were diagnosed as Medulloblastoma. Age distribution of the patient is shown in Table no. 1 and Figure no.1A. Most common age group was 6-12 year (52.63\%) and it was found to be statistically significant ( $p=0.000001)$. male predominance was reported (M:F-2.1:1) and it is statistically significant $(\mathrm{p}=0.00023)$ (Table no.1 and Figure no.1B). In the present study all tumor reside at infra-tentorial region, while tumor from any other site was not reported. Increased intracranial pressure was reported in $17(89.47 \%)$ cases and it was normal in $2(10.52 \%)$ cases, which is statistically significant $(\mathrm{p}=0.000395)$ (Table no.1 and Figure no.1C). hydrocephaly was reported only in $3(15.78 \%$ ) cases (Table no.1 and Figure no.1D). Most frequent tumors in our study was classical type of Medulloblastoma $(n=18,94.74 \%)$ while only case of Desmoplastic (5.26\%) type was reported. Most common symptom was headache $(n=17,89.47 \%)$ followed by emesis, lethargy and nausea $(n=1,5.26 \%)$ and cerebellar sign $(n=1$, $5.26 \%$ ). Histopathological findings of Medulloblastoma Classical variant and desmoplastic variant is shown in Figure no 2 and 3 respectively. 
Table 1. Patient variable in present study.

\begin{tabular}{|c|c|c|c|}
\hline Variable & No. Of cases & Percentage & Pvalue \\
\hline \multicolumn{4}{|l|}{ Age group } \\
\hline$<6$ years & 05 & $26.31 \%$ & \multirow{4}{*}{0.000001} \\
\hline $6-12$ years & 10 & $52.63 \%$ & \\
\hline $13-20$ years & 02 & $10.52 \%$ & \\
\hline$>20$ years & 02 & $10.52 \%$ & \\
\hline \multicolumn{4}{|l|}{ Gender } \\
\hline Male & 13 & $68.42 \%$ & \multirow{2}{*}{0.000230} \\
\hline Female & 06 & $31.58 \%$ & \\
\hline \multicolumn{4}{|l|}{ Site } \\
\hline Infratentorial & 19 & $100 \%$ & \multirow{2}{*}{0.000001} \\
\hline Others & 0 & 0 & \\
\hline \multicolumn{4}{|l|}{ Intracranial pressure } \\
\hline Normal & 02 & $10.52 \%$ & \multirow{2}{*}{0.000395} \\
\hline Increased & 17 & $89.47 \%$ & \\
\hline \multicolumn{4}{|l|}{ Hydrocephalus } \\
\hline Present & 16 & $84.21 \%$ & \multirow{2}{*}{0.000230} \\
\hline Absent & 03 & $15.78 \%$ & \\
\hline \multicolumn{4}{|l|}{ Histological type } \\
\hline Classical & 18 & $94.74 \%$ & \multirow{2}{*}{0.000001} \\
\hline Desmoplastic & 01 & $5.26 \%$ & \\
\hline \multicolumn{4}{|l|}{ Signs and symptoms } \\
\hline Headache & 17 & $89.47 \%$ & \multirow{3}{*}{0.000002} \\
\hline Emesis, Lethargy, Nausea & 01 & $5.26 \%$ & \\
\hline Cerebellar signs & 01 & $5.26 \%$ & \\
\hline
\end{tabular}
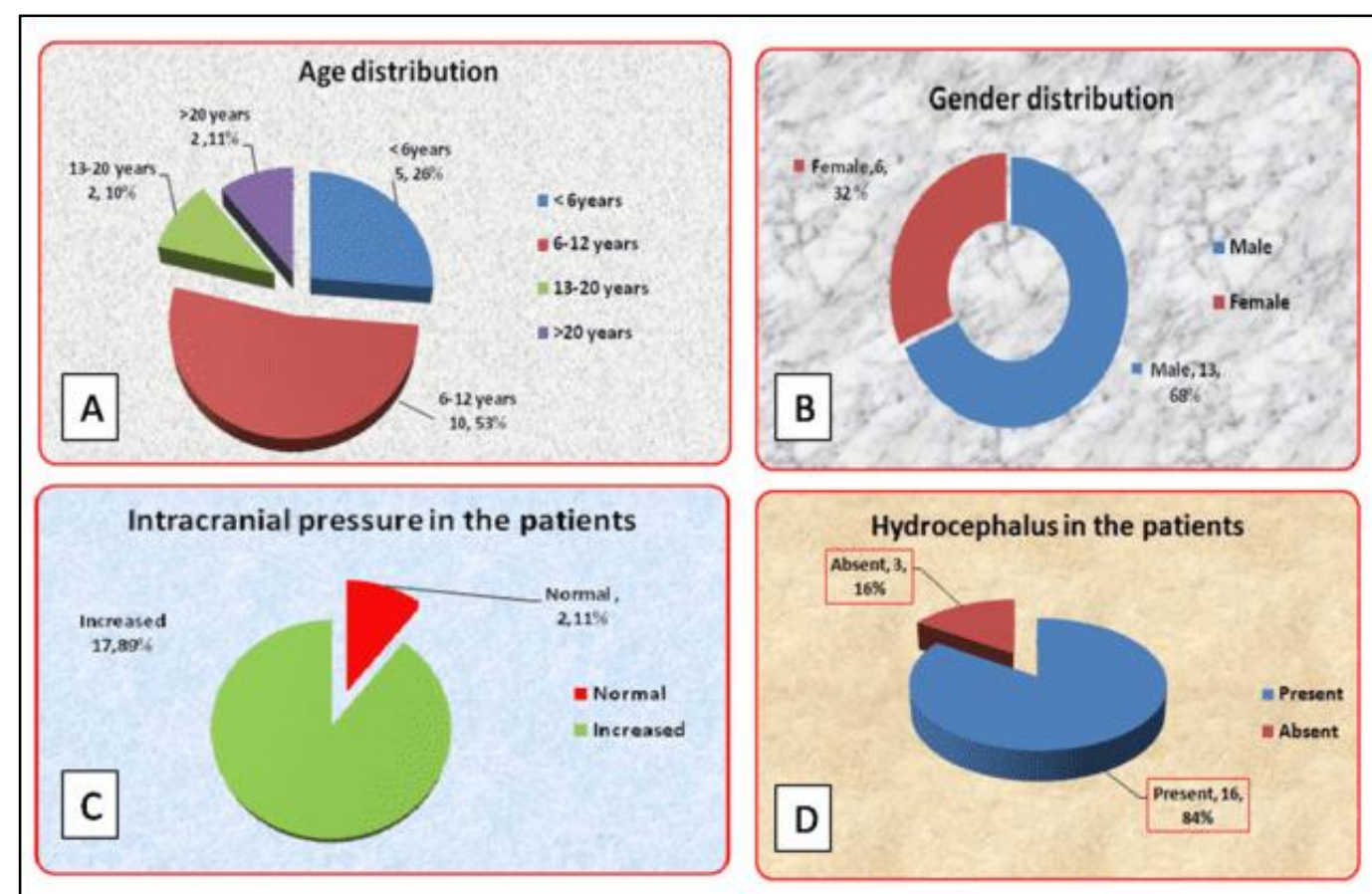

Figure 1. A. Age distribution, B. Gender distribution, C. Intracranial pressure, D. Hydrocephalus. 

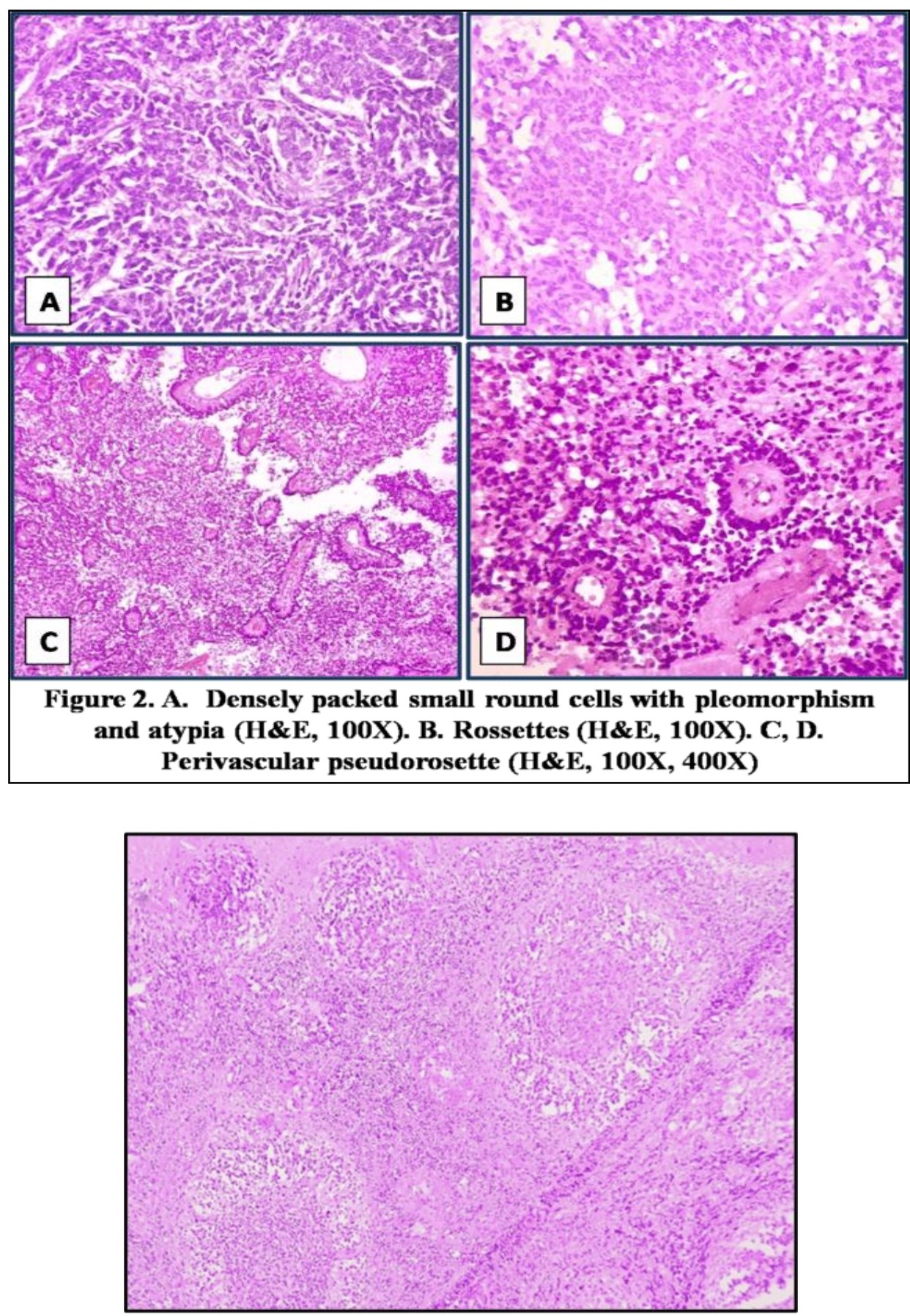

Figure. 3 Desmoplastic/nodular variant of Medulloblastoma (H\&E, 100X)

\section{Discussion}

In the present study, Medulloblastoma was diagnosed according to 2016 World Health Organization Classification of Tumors of the Central Nervous System. Among 19 patients of Medulloblastoma most common age group was 612 year and it was similarly reported by Kadri $\mathrm{H}$ et al $2005^{[8]}$ and Nasir $\mathrm{S}$ et al $2010^{[9]}$, in their study most common age group is less than 14 years. This result of our study in correspondence to other studies confirms that Medulloblastoma is a tumor of childhood. ${ }^{[10]}$

In our study Medulloblastoma predominately present in male (M:F - 2.16:1). The male:female ratio in our study coincides with other studies, like that of Saima Nasir et al ${ }^{[10]}$, Memon et al and Rehman et $\mathrm{al}^{[11,12]}$. The tumor has an overall maleto-female ratio of 1.7:1 reported globally ${ }^{[1]}$.

All cases of Medulloblastoma, in our study were found in infra-tentorial region while in other 
studies; Ahmed et al., 2007; Kadri et al., 2005 and Khan et al., 2009 reported that $60-70 \%$ tumors in above said location ${ }^{[13,14,15]}$. However, Pollack (1999) reported higher number of supratentorial tumors (52\%) as compared to infratentorial tumors $(48 \%)^{[16]}$

Medulloblastomas growing in the fourth ventricle cause increased intracranial pressure by exerting mass effect and blocking cerebrospinal fluid pathways. Therefore, most patients present with a short history of raised intracranial pressure: headaches that have increased in frequency and severity, frequent nausea upon waking, and bouts of vomiting. Cerebellar ataxia is common ${ }^{[1]}$. In our study also raised intracranial pressure was found in 17 out of 19 cases and 16 of them had hydrocephalus. Most of them (17/19) presented with headache as a presenting complaint. Emesis and cerebellar signs were recorded as primary complaint in one case each. In a large study conducted in an Indian institute dedicated to oncology, for a period of 10 years, Gaur et al recorded the first symptom in the maximum number of cases as raised intracranial pressure $(93.10 \%)$ manifesting as headache, vomiting and hydrocephalus. Ataxia and progressive weakness were the other early manifesting signs. Raised intracranial pressure developed in $98.2 \%$ cases eventually ${ }^{[17]}$.

Histological analysis in our study revealed mostly classical features of Medulloblastoma. Most of the tumors had densely packed small round cells in sheets and perivascular pseudorosseting as arrangement. The cells showed mild to moderate atypia with frequent mitoses. In only one case $(5.26 \%)$ the features of desmoplastic/nodular variant of Medulloblastoma was seen. This tumor was cerebellar in location confirming that desmoplastic/nodular variant is mostly found in cerebellar hemispheres as reported by Buhren et al. ${ }^{[18]}$

Desmoplastic/nodular medulloblastomas are estimated to account for $20 \%$ of all medulloblastomas ${ }^{\{19\}}$. In one retrospective cohort of adult patients, desmoplastic/ nodular medulloblastoma constituted $21 \%$ of all medulloblastomas ${ }^{\{20\}}$. The lower incidence of this variant of Medulloblastoma reported in our study can be attributed to smaller number of cases studied.

\section{References}

1. IARC; Lyon 2016. David N. Louis, Hiroko Ohgaki, Otmar D. Wiestler, Webster K. Cavenee (Eds): WHO Classification of Tumours of the Central Nervous System (Revised 4th edition).

2. Dorner L, Fritsch MJ, Stark AM, Mehdorn HM. Posterior fossa tumors inchildren: how long does it take to establish the diagnosis? Childs Nerv Syst.2007 Aug;23(8):887-90. Epub 2007 Apr 12. PubMed PMID: 17429658.

3. Molineus A, Boxberger N, Redlich A, Vorwerk P. Time to diagnosis of brain tumors in children: a single-centre experience. Pediatr Int. 2013 Jun;55(3):3059. doi: 10.1111/ped.12095. PubMed PMID: 23480630. 1.

4. Bailey CC, Gnekow A, Wellek S, Jones M, Round C, Brown J, et al. Prospective randomized trial of chemotherapy given before radiotherapy in childhood medulloblastoma. Inter-national Society of Pediatric Oncology (SIOP) and the German Society of Paediatric Oncology (GPO): SIOP II.Med Pediatr Oncol1995;25:166-78.

5. Jenkin D, Shabanah MA, Shail EA, Gray A, Hassounah M, Khafaga Y, et al. Prognostic factors for medulloblastoma. Int $\mathrm{J}$ Radiat Oncol Biol Phys 2000;47:573-84.

6. Zeltzer PM, Boyett JM, Finlay JL, Albright AL, Rorke LB,Milstein JM, et al. Metastasis stage, adjuvant treatment, and residual tumor are prognostic factors for Medulloblastoma in children: conclusions from the Children's Cancer Group 921 randomized Phase III study.J Clin Oncol 1999; 17:832- 45 . 
7. Packer RJ, Goldwein J, Nicholson HS, Vezina LG, Allen JC, Ris MD, et al. Treatment of children with medulloblastomas with reduced-dose craniospinal radiation therapy and adjuvant chemotherapy: a Children's Cancer Group study.J ClinOncol1999;17:2127-36.

8. Kadri H, Mawla AA, Murad L (2005). Incidence of childhood brain tumors in Syria (1993- 2002). Childs Nerve Syst, 41, 173-7

9. Nasir S, i Jamila B, Khaleeq S . A Retrospective Study of Primary Brain Tumors in Children under 14 Years of Age at PIMS, Islamabad. Asian Pacific Journal of Cancer Prevention, Vol 11, $2010 \mathrm{p}$ 1225-27.

10. Saima Nasir, Bibi Jamila, Samina Khaleeq. A Retrospective Study of Primary Brain Tumors in Children under 14 Years of Age at PIMS, Islamabad. Asian Pacific J Cancer. Asian Pacific Journal of Cancer Prevention, Vol 11, 2010. P 1225-1227.

11. Memon F, Rathi SL, Memon MH (2007). Pattern of solid paediatric malignant neoplasm at LUMHS, Jamshoro, Pakistan. J Ayub Med Coll Abbottabad, 19, 55-7.

12. Rehman AU, Lodhi S, Murad S (2009). Morphological pattern of posterior cranial fossa tumors. Ann KEMU, 15, 57-9.

13. Ahmed N, Bhurgri Y, Sadiq S, et al (2007). Pediatric brain tumours at a tertiary care hospital in Karachi. Asian Pac J Cancer Prev, 8, 399-404.

14. Kadri H, Mawla AA, Murad L (2005). Incidence of childhood brain tumors in Syria (1993-2002). Childs Nerve Syst, 41, 173-7.

15. Khan K, Qureshi AN, Bibi P, et al (2009). Accuracy of computerised tomography in diagnosis of brain tumours in children. $J$ Ayub Med Coll Abbottabad, 21, 42-4.
16. Pollack IF (1999). Pediatric brain tumors. Semin Surg Oncol, 16, 73-90.

17. Gaur S, Kumar SS, Balasubramaniam P. An analysis of medulloblastoma: 10 year experience of a referral institution in South India. Indian J Cancer. 2015 OctDec;52(4):575-8. doi: 10.4103/0019509X.178404. PubMed PMID: 26960482.

18. Buhren J, Christoph AH, Buslei R, Albrecht S, Wiestler OD, Pietsch T (2000). Expression of the neurotrophin receptor p75NTR in medulloblastomas is correlated with distinct histological and clinical features: evidence for a medulloblastoma subtype derived from the external granule cell layer, J NeuropatholExp Neurol.

19. Pietsch T, Schmidt R, Remke M, Korshunov A, Hovestadt V, Jones DT, et al.(2014). Prognostic significance of clinical, histopathological, and molecular characteristics of medulloblastomas in the prospective HIT2000 multicenter clinical trial cohort. Acta Neuropathol. 128(1 ):13749.PMID:24791927

20. Korshunov A, Remke M, Werft W, Benner A, Ryzhova M, Witt H, et al. (2010). Adult and pediatric medulloblastomas are genetically distinct and require different algorithms for molecular risk stratification. J Clin Oncol.28(18):3054-60. PMID:20479417. 